\title{
Neonatal Dubin-Johnson Syndrome: Long-Term Follow-up and MRP2 Mutations Study
}

\author{
JYH-HONG LEE, HUEY-LING CHEN, HUI-LING CHEN, YEN-HSUAN NI, HONG-YUAN HSU, AND MEI-HWEI CHANG
}

Department of Pediatrics [J.-H.L., Huey-L.C., Y.-H.N., H.-Y.H., M.-H.C.], Primary Care Medicine [Huey-L.C.], Hepatitis Research Center [Hui-L.C.], National Taiwan University College of Medicine and National Taiwan University Hospital, Taipei 100, Taiwan

\begin{abstract}
Neonatal Dubin-Johnson syndrome (DJS) is rarely diagnosed and mutational analysis of multidrug-resistance-associated protein 2 (MRP2) in such patients had not been reported. We aimed to investigate the possible correlations between genotype and phenotype of patients with DJS. Four cases of DJS, two diagnosed during the neonatal period and two diagnosed at adolescence, were followed for 5-20 y. Mutational analysis in the MRP2/ABCC2 gene was performed in all four cases. Biphasic pattern of jaundice attack was observed in one patient who was followed for $20 \mathrm{y}$, with jaundice subsiding before $1 \mathrm{y}$ of age and recurring at adolescence. Six novel mutations in four patients were found, including deletions (2748del136, 3615del229, and Del3399-3400), and missense mutations (L441M and E1352Q) and nonsense mutation (Y1275X). The immunohistochemical staining in liver tissues from two patients with neonatal onset showed negative staining for MRP2. Reviewing previously reported cases, all patients diagnosed as DJS before $10 \mathrm{y}$ of age have mutations involving one of the two ATP-binding cassettes (ABC) of the MRP2. This study suggests that long-term follow-up is indicated for neonatal DJS because of possible recurrence and/or second attacks of jaundice in later life, and that disruption of functionally important ABC domains in MRP2 may be related to the earlier onset of the disease. (Pediatr Res 59: 584-589, 2006)
\end{abstract}

D JS is an autosomal recessive disease with clinical features of chronic or intermittent conjugated hyperbilirubinemia, a defect in the excretion of anionic conjugate from the hepatocyte into the bile, delayed clearance of intravenous bromosulfophthalein (BSP), increased urinary excretion of coproporphyrin I, and hepatic histopathology of lysosomal accumulation of black pigment (1-3). Most patients are asymptomatic, although some patients presented with vague right-upper-quadrant abdominal pain, weakness, nausea, or vomiting. Physical examination is frequently normal or unremarkable. Jaundice is evident by the time of puberty in about half, and by the age of 20 in about two-thirds, of affected persons (1). Liver enzymes are usually within normal limits, although the bilirubin levels fluctuate (1).

The molecular mechanism in DJS is impaired hepatobiliary excretion of anionic conjugate caused by the defects of MRP2 or cMOAT $(4,5)$. The formal genetic name is $A B C C 2$. MRP2

Received May 27, 2005; accepted November 21, 2005.

Correspondence: Mei-Hwei Chang, M.D., Department of Pediatrics, National Taiwan University Hospital, 7F, No. 7, Chung-Shan South Rd., Taipei 100, Taiwan; e-mail: mhchang@ha.mc.ntu.edu.tw

DOI: 10.1203/01.pdr.0000203093.10908.bb protein acts as an ATP-dependent export pump for anionic glutathione or glucuronate conjugate from hepatocyte into bile and is expressed at the apical/canalicular plasma membrane of hepatocyte (6). The MRP2 protein is a member of the ABC transporter superfamily. The predicted topology of the MRP2 protein contains three MSD and two ABC (7). The ABC are functional regions responsible for nucleotide binding and have three motifs: Walker A, Walker B, and the signature C motif. These motifs are important for ATP binding and are highly conserved among members of the $\mathrm{ABC}$ transporter superfamily $(7,8)$.

The human $A B C C 2$ gene is localized to chromosome 10q24, spans about $45 \mathrm{~kb}$, and contains 32 exons (9). The first mutation of $A B C C 2$ gene responsible for DJS was detected in 1997 (10). Subsequently, 12 different mutations in the $A B C C 2$ gene have been reported in DJS patients, including three splice-site mutations at the donor site resulting in exon skipping, five missense mutations, three nonsense mutations, and one deletion of 6 bases $(8,10-18)$. These mutations cause defects in the maturation and localization of the MRP2 protein by disrupting protein synthesis, exchanging amino acids, changing protein structures at different locations of the MRP2 protein, and impairing its trafficking to target locations $(5,15,19,20)$.

DJS is rarely diagnosed in the neonatal period and its presentation as severe cholestasis is uncommon in neonates (21-28). There has been no report on long-term follow-up and genetic studies of DJS with a neonatal onset. Furthermore, it is not known whether neonatal DJS is caused by MRP2 mutations.

In this report, we describe four neonatal DJS patients and perform mutational analysis. There are many published studies describing clinical characteristics of DJS (genotype) and the types of mutations associated with DJS (phenotype); however, this study focused on the relationship between the disease onset and mutation type are lacked. In this study, we also performed a comprehensive review of the literature, focusing on the possible correlations between the $A B C C 2$

Abbreviations: ABC, ATP-binding cassette; ABCC2, ABC, subfamily C, member 2; ALT, alanine aminotransferase AST, aspartate aminotransferase; cMOAT, canalicular multispecific organic anion transporter; DJS, DubinJohnson syndrome; MRP2, multidrug-resistance associated protein 2; MSD, membrane spanning domains 
gene genotype and the clinical presentations (phenotype) of DJS.

\section{CASE REPORTS}

Four patients were included according to the clinical characteristics and hepatic pathology compatible with the diagnosis of DJS in the National Taiwan University Hospital. Two of the patients had an onset of cholestasis confirmed by biochemistry and pathology since the neonatal period, whereas the other two had a history of neonatal jaundice and their hyperbilirubinemia was documented since early adolescence. Informed consent was obtained from the patients, parents, and family members. The study has been approved by the Institutional Review Board.

Case $\boldsymbol{A}$. The yellowish skin was first noted $7 \mathrm{~d}$ after birth and the laboratory data showed a total bilirubin level of $319.8 \mu \mathrm{M}$. Phototherapy was given and the laboratory data after treatment showed a total bilirubin level of $153.9 \mu \mathrm{M}$ at $10 \mathrm{~d}$ of age. The patient was admitted to our hospital at $50 \mathrm{~d}$ of age and laboratory examinations showed bilirubin levels (total/direct) 280.4/ $259.9 \mu \mathrm{M}$ and AST/ALT) of 51/35 U/L. Abdominal ultrasonography revealed mild hepatomegaly.

The jaundice subsided at the age of 9 mo. The follow-up physical examination showed nonpalpable liver and spleen, whereas laboratory examinations showed bilirubin (total/direct) 20.5/12.0 $\mu \mathrm{M}$ and AST/ALT 24/14 U/L when he was 5 y old. Liver biopsy at the age of 2 mo showed dark-brown-colored liver tissue in gross examination, and diffuse dark-brown granules in the hepatocytes and canalicular cholestasis in microscopy examination. These are compatible with DJS.

Case B. A male patient had jaundice since $3 \mathrm{~d}$ of age and the jaundice subsided gradually but reappeared at $20 \mathrm{~d}$ of age. The detailed clinical history had been reported (23). The laboratory examination showed bilirubin levels (total/direct) of $116.3 / 97.5 \mu \mathrm{M}$. At $2.5 \mathrm{mo}$ old, the bilirubin levels (total/ direct) were 145.4/95.8 $\mu \mathrm{M}$ and AST/ALT were 60/29 U/L. Abdominal ultrasonography revealed a homogenously enlarged liver with a normal biliary tree. Liver biopsy was conducted, which showed grayish-colored liver tissue on gross examination and paucity of the interlobular bile duct with prominent intracellular and canalicular cholestasis microscopically. The BSP study revealed positive results of delayed clearance and double peaks.

A second liver biopsy was done at 6 y of age and showed blackish-colored liver tissue grossly, with mild portal fibrosis and diffuse deposition of coarsely granular, brownish pigment in the hepatocytes microscopically, which were compatible with DJS. The follow-up physical examination showed nonpalpable liver and spleen. Laboratory examination showed bilirubin levels (total/direct) of $44.5 / 32.5 \mu \mathrm{M}$ and AST/ALT of 10/11 U/L when he was $21 \mathrm{y}$ old.

Case $\boldsymbol{C}$. This patient was diagnosed with neonatal hyperbilirubinemia soon after birth. No laboratory data were available. He did not received phototherapy and the prolonged hyperbilirubinemia subsided in young infancy. Jaundice was noted at $10 \mathrm{y}$ of age during an upper respiratory infection episode but it subsided 2 wk later. At 14 y old, he complained of fever, yellowish skin discoloration, and general malaise. The laboratory examination showed bilirubin levels (total/direct) of 124.8/46.2 $\mu \mathrm{M}$ and AST $28 \mathrm{U} / \mathrm{L}$.

At $14 \mathrm{y}$ old, he underwent liver biopsy, which showed a dark-greenishcolored liver tissue on gross examination and the presence of coarse, granular, dark-brownish pigments predominantly in the centrilobular hepatocytes microscopically. These were compatible with DJS. Follow-up laboratory examination at $23 \mathrm{y}$ of age showed bilirubin (total/direct) of 99.2/51.3 $\mu \mathrm{M}$ and AST/ALT of 18/17 U/L. Abdominal ultrasonography showed negative result.

Case $\boldsymbol{D}$. The patient was diagnosed with neonatal hyperbilirubinemia soon after birth. He received phototherapy for more than $20 \mathrm{~d}$ and the jaundice subsided gradually. He was noted to have icteric skin since $14 \mathrm{y}$ of age and icteric sclera since $17 \mathrm{y}$ of age. When he was $18 \mathrm{y}$ old, a laboratory examination showed bilirubin levels (total/direct) of $65.0 / 41.0 \mathrm{mg} / \mathrm{dL}$ and AST/ALT of 19/12 U/L. Abdominal ultrasonography showed negative results. Liver biopsy at $18 \mathrm{y}$ old showed a dark-brownish-colored liver tissue grossly and numerous golden-yellow pigments in hepatocytes microscopically. Follow-up physical examination showed nonpalpable liver and spleen, whereas laboratory examination showed bilirubin level (total/direct) of 79.3/ $38.8 \mathrm{mg} / \mathrm{dL}$ and AST/ALT of $15 / 13 \mathrm{U} / \mathrm{L}$ at $22 \mathrm{y}$ of age.

\section{METHODS}

mRNA analysis and direct sequencing of cDNA. Total cellular RNA was extracted from frozen liver biopsy samples by RNeasy Mini-kit (QIAGEN, Hilden, Germany). The cDNA from isolated total RNA was obtained by reverse transcription (RT) using random hexamers (Promega, Madison, WI) and SuperScript II Reverse Transcriptase (Invitrogen, Carlsbad, CA) at $42^{\circ} \mathrm{C}$ for $50 \mathrm{~min}$ and inactivated at $70^{\circ} \mathrm{C}$ for $15 \mathrm{~min}$. The cDNA was subjected to PCR using TaqDNA polymerase (Biotools B\&M Labs, Madrid, Spain) and eight sets of primers were used: DJ-1S 5'-CTT TGT TCC AGA CGC AGT CC-3'; DJ-1A 5'-CAA CTT CCC AGA CAT CC TCG-3'; DJ-2S 5'-CTG AAA GGC TAC AAG CGT CC-3'; DJ-2A 5'-AGG GTC CCA ACT CTC TCC AT-3'; DJ-3S 5'-CAC ATG CTG TGG TCA AGT GTT-3'; DJ-3A 5'-TGC CAT AAT GTC CAG GTT CA-3'; DJ-4S 5'-TCT GAG GCC TCC TTT ACC TG-3'; DJ-4A 5'-CAT GGA CTG TGG CTT CCT CT-3'; DJ-5S 5'-TCC TAC AGT GCT CTC CTG GC-3'; DJ-5A 5'-CCT GTG GGT GTT GTG TCA AA-3'; DJ-6S 5'-TGC ACA AGC AAC TGC TGA AC-3'; DJ-6A $5^{\prime}$-CGG AGG CCT CTT ATC AGT CA-3'; DJ-7S 5'-ACC AAC ATT GTG GCT GTT GA-3'; DJ-7A 5'-TTG GAT GGT CGT CTG AAT GA-3'; DJ-8S 5'-ACG AAG TGA CAG AGG CTG GT-3'; DJ-8A5'-TGG GTA GTA GGT TCA TGG GTG- ${ }^{\prime}$, deduced from the entire coding sequence of the $A B C C 2$ gene. The PCR products from cDNA were subjected to direct DNA sequencing. Sequence analysis was performed by the dideoxynucleotide chaintermination method using the ABI 377 DNA Automated Sequencer (Applied Biosystems, Foster City, CA).

Genomic DNA analysis. Mutations found on the cDNA were confirmed by sequencing the corresponding exons in genomic DNA. Genomic DNA was isolated from the frozen liver samples using the QIAamp DNA Mini-kit (QIAGEN), or from peripheral blood leukocytes using the Puregene DNA isolation kit (Gentra, Minneapolis, MN). The PCR amplification of selected exons (exons 15, 16, 17, 25, 26, 27 of patient A; exons 10, 15, 16, 17, 24, 25 of patient C; and exons $9,10,15,17$ of patient D) was performed using the primer sets previously reported (13). Genomic DNA sequencing was performed in all exons of patient B. Direct DNA sequencing analysis was performed as described above. A family study of patient $\mathrm{D}$, which included both parents and two sisters, was also conducted.

Immunohistochemical staining. Samples of liver tissue were obtained from patient A and B when they received liver biopsies during the neonatal period. Samples of liver tissue from adults were obtained from the nontumor part of liver resection for hepatocellular carcinoma with informed consent. Liver slices were embedded in Tissue-Tek and stored at $-80^{\circ} \mathrm{C}$. Tissue sections of 5-7 $\mu \mathrm{m}$ were cut in cryostat at $-20^{\circ} \mathrm{C}$ and placed on poly-L-lysinecoated glass slides, then fixed in acetone for $10 \mathrm{~min}$ at room temperature.

An immunohistochemical staining kit was used (HRP-DAB System, R \& D Systems, Minneapolis, MN). Endogenous peroxidase activity was blocked with $0.03 \% \mathrm{H}_{2} \mathrm{O}_{2}$ for $5 \mathrm{~min}, 10 \%$ normal human serum for $15 \mathrm{~min}$, avidin blocking reagent for $15 \mathrm{~min}$, rinsed with PBS, then incubated with biotin blocking reagent for $15 \mathrm{~min}$. A rabbit polyclonal antibody against carboxyl terminal of human bile salt export pump (BSEP) sequences KGAYYKLVTTGAPIS was used (29). MAb against human MRP2 (M III-6) were obtained from Alexis Biochemicals (San Diego, CA). Sections were incubated with the rabbit anti-BSEP antibody (final dilution 1:300) and mouse anti-MRP2 antibody (final dilution 1:20), respectively, in a humid chamber for $2 \mathrm{~h}$. After a washing step with PBS, the tissue sections were incubated with biotinylated secondary antibody to either rabbit or mouse IgG for $1 \mathrm{~h}$, followed by washing with PBS, and incubated with high-sensitivity streptavidin conjugated to horse-radish peroxidase (HSS-HRP; R \& D Systems, Minneapolis, MN) for $30 \mathrm{~min}$. The sections were washed and incubated with diaminobenzidine chromogen DAB; Signet Laboratories, Dedham, MA) chromogen solution for 3-5 min. After a final washing step, the sections were mounted with ENTELLAN (Merck, Darmstadt, Germany) and examined under Leica DMRD microscope (Leica, Wetzlar, Germany) and images were documented by CoolSnap cooled CCD camera image capture system.

Correlation between age of onset and specific mutation type by literature review. Relevant English literature was identified by performing MEDLINE/ Pubmed searches from January 1990 to December 2004. Combinations of the following search terms were use to analyze these databases: Dubin-Johnson syndrome, mutation, MRP2, cMOAT, ABCC2. A total of 261 articles were identified; 15 met inclusion criteria for literature review. We further chose patients with clear descriptions of clinical manifestation of DJS, age of onset, mutational analysis, and specific type of mutation.

\section{RESULTS}

The clinical characteristics and genetic mutations of all of the four neonatal DJS patients are summarized in Table 1. The representative follow-up time course of serum levels of bilirubin of patient B is shown in Figure 1.

Mutational analysis. Mutational analysis of the $A B C C 2$ gene of patient A revealed two mutations. One is a heterozy- 
Table 1. Clinical and genetic characteristics of the four patients with DJS

\begin{tabular}{|c|c|c|c|c|c|c|c|}
\hline Case & $\begin{array}{c}\text { Sex/age at } \\
\text { onset }\end{array}$ & $\begin{array}{l}\text { Presenting } \\
\text { symptoms }\end{array}$ & $\begin{array}{l}\text { Peak bilirubin } \\
\text { (total/direct)* }^{*}\end{array}$ & $\begin{array}{l}\text { Follow-up } \\
\text { durations }\end{array}$ & Hepatic pathology & MRP2/ABCC2 Genotype & Predicted effects \\
\hline A & $\mathrm{M} /$ neonate & $\begin{array}{l}\text { Jaundice and } \\
\text { mild hepato- } \\
\text { megaly }\end{array}$ & $280.4 / 259.9$ & Newborn to $5 \mathrm{y}$ & $\begin{array}{l}\text { Diffuse dark-brownish } \\
\text { granule in hepatocytes } \\
\text { with canalicular } \\
\text { cholestasis }\end{array}$ & $\begin{array}{l}\text { 4054G } \rightarrow \mathrm{C} \text {, heterozygous } \\
3615 \mathrm{del} 229 \text {, heterozygous }\end{array}$ & $\begin{array}{l}\text { 1352Q at 2nd ABC } \\
\text { Truncation at junction of } \\
\text { MSD3 and 2nd ABC }\end{array}$ \\
\hline $\mathrm{B}$ & $\mathrm{M} /$ neonate & $\begin{array}{l}\text { Jaundice and } \\
\text { hepatomegaly }\end{array}$ & $164.2 / 112.9$ & Newborn to $21 \mathrm{y}$ & $\begin{array}{l}\text { Diffuse coarsely } \\
\text { granular, brownish } \\
\text { pigment in } \\
\text { hepatocytes and mild } \\
\text { portal fibrosis }\end{array}$ & $\begin{array}{l}\text { 2748del136, heterozygous } \\
3825 \mathrm{C} \rightarrow \mathrm{G} \text {, heterozygous }\end{array}$ & $\begin{array}{l}\text { Truncation since MSD3 } \\
\text { and loss of } 2 \text { nd ABC } \\
\text { Truncation at junction of } \\
\text { MSD3 and 2nd ABC }\end{array}$ \\
\hline $\mathrm{C}$ & $\mathrm{M} / 10 \mathrm{y}$ & $\begin{array}{l}\text { Jaundice and } \\
\text { general malaise }\end{array}$ & $138.5 / 54.7$ & $10 \mathrm{y}$ to $23 \mathrm{y}$ & $\begin{array}{l}\text { Coarsely granular and } \\
\text { dark-brownish } \\
\text { pigments in } \\
\text { centrilobular } \\
\text { hepatocytes }\end{array}$ & $\begin{array}{l}1321 \mathrm{C} \rightarrow \mathrm{A}, \text { heterozygous } \\
\text { Del3399-3400, } \\
\text { heterozygous }\end{array}$ & $\begin{array}{l}\text { L441M at MSD2 } \\
\text { Truncation within MSD3 } \\
\text { and loss of 2nd ABC }\end{array}$ \\
\hline $\mathrm{D}$ & $\mathrm{M} / 14 \mathrm{y}$ & Jaundice & $79.3 / 38.87$ & $14 \mathrm{y}$ to $22 \mathrm{y}$ & $\begin{array}{l}\text { Golden-yellowish } \\
\text { pigments in } \\
\text { canalicular portion of } \\
\text { hepatocytes }\end{array}$ & $1177 \mathrm{C} \rightarrow \mathrm{T}$, homozygous & R393W at MSD2 \\
\hline
\end{tabular}

* Bilirubin level normal range: total/direct $<34 / 3.4 \mu \mathrm{mol} / \mathrm{L}$.

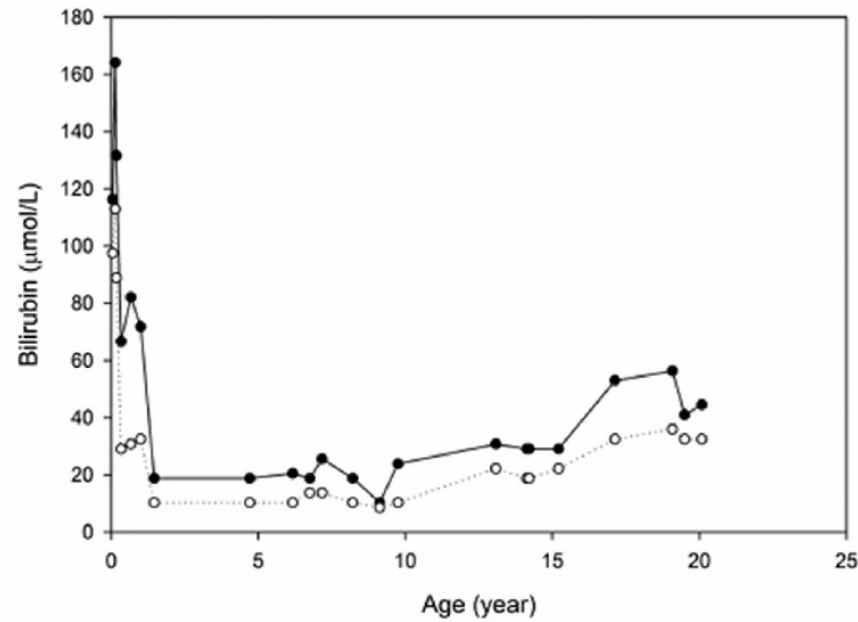

Figure 1. The time course of serum levels of total $(-)$ and direct $(\bigcirc)$ bilirubin in patient B. A biphasic pattern in the appearance of hyperbilirubinemia was noted.

gous deletion mutation 3615 del229, resulting in the skipping of exons 26 and 27 and the introduction of a premature termination codon in exon 28 . The predicted effect is a truncated MRP2 protein at the junction of MSD3 and the second $\mathrm{ABC}$, leading to the loss of the entire second $\mathrm{ABC}$. The other mutation is a heterozygous single nucleotide transition from $\mathrm{G}$ to $\mathrm{C}$ at nucleotide 4054 , which resulted in a missense mutation of Glu1352Gln (E1352Q) in exon 29, located between Walker $\mathrm{A}$ and the signature $\mathrm{C}$ motif of the second $\mathrm{ABC}$ that is highly conserved in all mammalian MRP2.

Mutational analysis in cDNA of patient B revealed a heterozygous deletion mutation 2748del136, which resulted in the skipping of exon 21 . The predicted effect is a premature truncation at MSD3, thus losing the entire second $\mathrm{ABC}$. The other mutation, a heterozygous single nucleotide transition from $\mathrm{C}$ to $\mathrm{G}$ at nucleotide 3825 , resulting in a nonsense mutation Y1275X in exon 27, was found in genomic DNA. The predicted effect is a truncated MRP2 protein at the junction of MSD3 and the second $\mathrm{ABC}$, leading to the loss of the entire second $\mathrm{ABC}$.

Mutational analysis of the $A B C C 2$ gene of patient $\mathrm{C}$ revealed two mutations. One is a heterozygous single nucleotide transition from $\mathrm{C}$ to $\mathrm{A}$ at nucleotide 1321, which resulted in a missense mutation Leu441Met (L441M) in exon 10, located within MSD2 which was highly conserved. The other one is a heterozygous Del 3399-3400, which resulted in a frame shift of 42 amino acids and the introduction of a premature termination in exon 24. The predicted effect was the disruption of protein synthesis within MSD3, with resultant loss of the second $\mathrm{ABC}$.

Mutational analysis of the $A B C C 2$ gene of patient $\mathrm{D}$ revealed a homozygous single nucleotide transition from $\mathrm{C}$ to $\mathrm{T}$ at nucleotide 1177, which resulted in Arg393Trp (R393W) in exon 9, a highly conserved site located within MSD2. This mutation had been recently reported (30). The family study revealed a heterozygous R393W mutation in both parents and two elder sisters. The other finding is a homozygous single nucleotide polymorphism from $\mathrm{G}$ to $\mathrm{A}$ at nucleotide 1249, which resulted in Val417Ile (V417I) in exon 10 that had been reported previously as a frequently nucleotide variations (31).

A summary of reported mutations (Table 2) and schematic representation of the locations of mutations affecting the $\mathrm{ABC}$ of the MRP2 protein described in the literature are shown (Fig. 2). A total of 15 mutations were found in nine patients diagnosed as DJS before $10 \mathrm{y}$ of age, including 10 mutations involving disruption of one of the two $\mathrm{ABC}$ of the MRP2, 4 missense mutations in the $\mathrm{ABC}$ regions, and 1 missense mutation in the membrane spanning domain. On the other hand, in 12 patients diagnosed after $10 \mathrm{y}$ of age, 14 mutations were found, including 6 mutations involving disruption of one 
Table 2. Summary of reported mutations affecting the ABC of the MRP2/ABCC2 protein

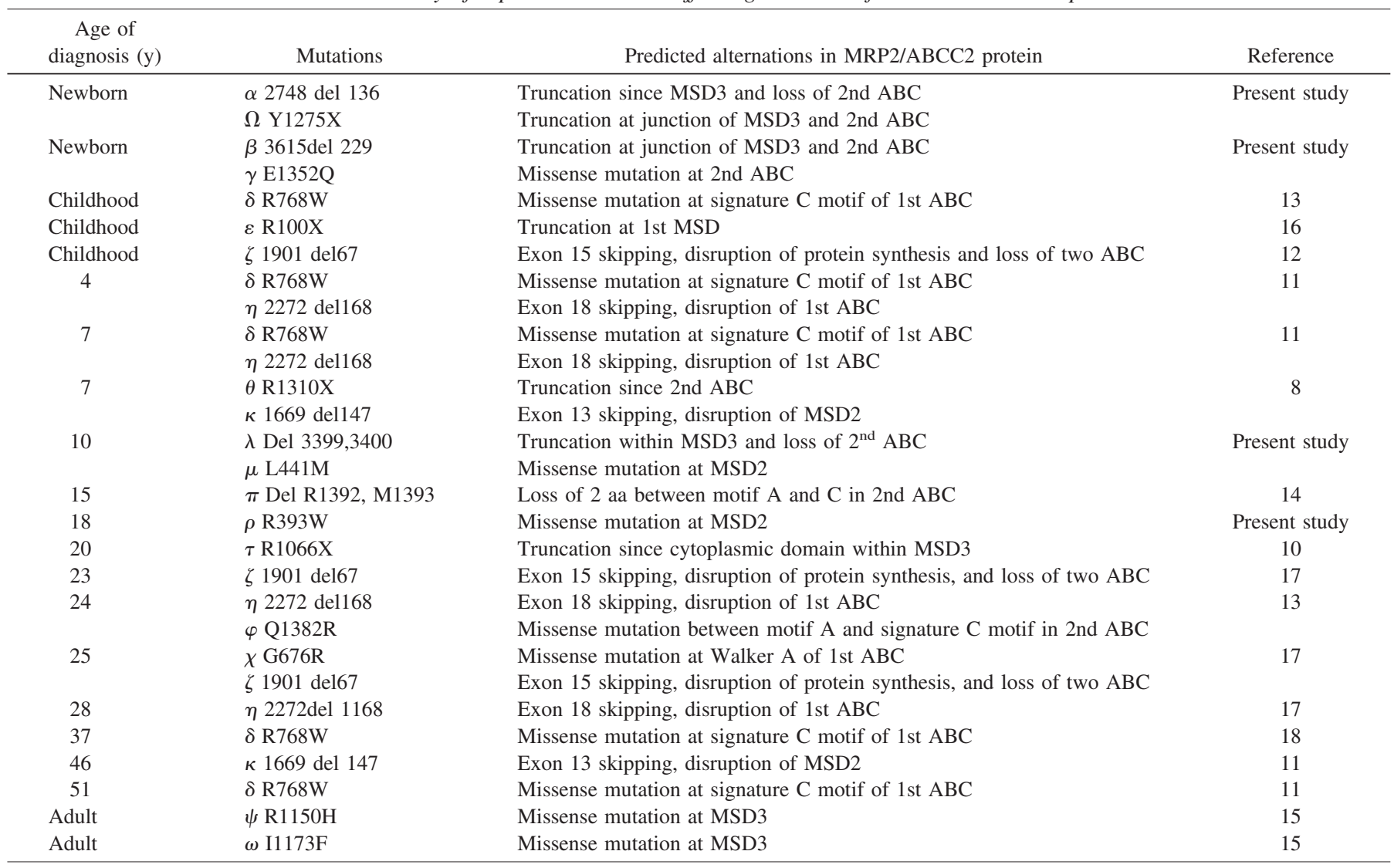

The approximate locations of mutations are represented as Greek characters $\alpha, \beta$, $\gamma$, etc. (also refer to Fig. 2).

MSDl MSD2
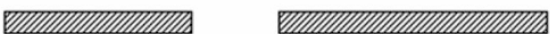

MSD3

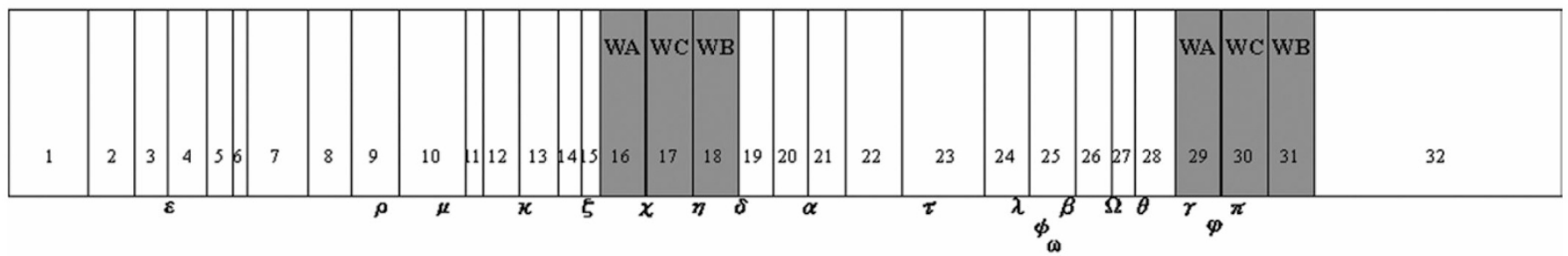

Figure 2. A schematic representation of the locations of various mutations in MRP2 protein described in patients with DJS. The exon number for each gene is represented by Arabic numerals from 1 to 32 in boxes. The Walker motifs $\mathrm{A}, \mathrm{B}$, and $\mathrm{C}$ within ATP-binding cassettes (ABC1 and $\mathrm{ABC} 2)$ are denoted as shaded boxes. The approximated locations of mutations are represented as Greek characters $\alpha, \beta$, $\gamma$, etc. (ref. 8,10-18, also refer to Table 2). WA,WB,WC, Walker motifs $\mathrm{A}, \mathrm{B}$, and $\mathrm{C}$, respectively.

of the two $\mathrm{ABC}$ of the MRP2 and 8 mutations involving a missense mutation in the $\mathrm{ABC}(5)$ or non-ABC (3) regions.

Immunohistochemical staining. The immunohistochemical staining of the liver tissue from patient B is shown (Fig. 3, $A-C$ ). Positive canalicular BSEP staining but negative MRP2 staining was shown in patient B. Patients A had similar results. The absence of MRP2 expression in patient A and B was in consistent with the predicted effect of truncated MRP2 protein synthesis resulting from deletion mutation 3615 del229 and mutations 2748del136/Y1275X, respectively.
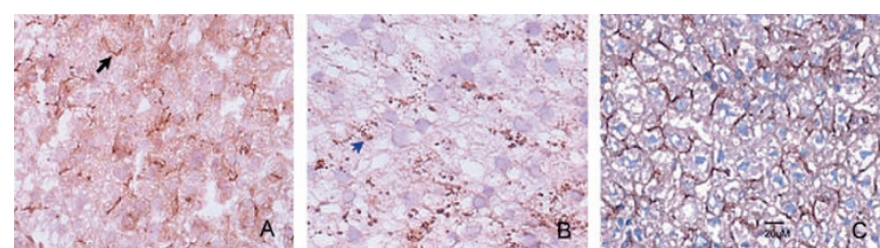

Figure 3. Immunohistochemical staining of patient B showed $(A)$ positive staining for canalicular protein BSEP (black arrows), $(B)$ but negative for MRP2. Some intracellular dark pigment granules typical for DJS were noted (blue arrow). (C) MRP2 staining of adult control liver showed normal canalicular pattern. (Original magnification $\times 400$.) 


\section{DISCUSSION}

To our knowledge, this is the first article reporting genetic analysis and long-term follow-up of neonatal DJS. All mutations in our study are novel, excepting that R383W has been recently reported (30), including three deletions, two missense mutations, and one nonsense mutation.

DJS is rarely diagnosed in the neonatal period and only a few cases have been reported (21-28). The clinical characteristics and diagnostic investigations are similar to adolescentor adult-onset DJS, except that more severe cholestasis and hepatomegaly may be found. Bilirubin levels could reach up to $>20 \mathrm{mg} / \mathrm{dL}(342 \mu \mathrm{M})(24)$. However, spontaneous recovery of serum bilirubin levels is expected within 6 mo (25). The serum transaminase levels are either within normal limits or mildly elevated (27). Effective management of severe forms of neonatal DJS with phenobarbital or ursodeoxycholic acid (UDCA) has been suggested $(24,28)$. In our study, patients A and $\mathrm{B}$ are confirmed cases of neonatal DJS with initial presentation of marked cholestasis and mild hepatomegaly. Patients $\mathrm{C}$ and $\mathrm{D}$ had histories of prolonged jaundice in neonatal period. It is possible that the neonatal jaundice of patients $\mathrm{C}$ and $\mathrm{D}$ were the initial presentation of DJS, similar to the biphasic pattern characteristic of patient B (Fig. 1).

In neonatal DJS, metabolic abnormalities of both bilirubin and bile acids were suggested as the possible causes of severe cholestasis (24). The expression of canalicular transporters is not yet mature in neonatal rat. During rat liver development, the MRP2 protein and BSEP are expressed as $50-60 \%$ of adult level at birth and increase to adult level by 1-3 wk of age, corresponding to the age of weaning (32). Immature expression and targeting of canalicular transporters were also found in human development (29). The immature bile physiology together with MRP2 defect may contribute to more severe manifestation in DJS patients in the neonatal period. It is possible that, in many cases, the first manifestations of neonatal hyperbilirubinemia caused by DJS are unnoticed early in life. As the liver matures, the patients may become asymptomatic until later in life when the influencing factors induce fluctuations of jaundice. We suggest that DJS should be included in the differential diagnosis of neonatal cholestasis.

Bilirubin levels are usually fluctuating in DJS patients (1). DJS usually manifests during puberty or in adults as mild conjugated hyperbilirubinemia, or intercurrent bouts of jaundice associated with pregnancy, drug intake, hormonal changes, or infections. From our long-term follow-up of DJS patients, we have observed a biphasic appearance of hyperbilirubinemia in patient $\mathrm{B}$, who has been followed-up for $20 \mathrm{y}$. The jaundice first subsided at around $1 \mathrm{y}$ of age and the patient remained asymptomatic during childhood. The jaundice recurred at adolescence and became evident at young adulthood, when most of the cases are diagnosed. As for patient A, the hyperbilirubinemia occurred at the neonatal period and persisted until the age of 9 mo, but remained asymptomatic until the last follow-up at the age of $5 \mathrm{y}$. Further follow-up is indicated for all neonatal DJS because of possible later recurrence.
This is the first report of MRP2 mutations in patients of Chinese descent. The mutations are different from those reported from Japanese patients. Most reported mutations of the $A B C C 2$ gene in DJS involve one or both $\mathrm{ABC}(8)$. These ABC are important for ATP binding and are highly conserved $(7,8)$. From reviewing reported cases, almost all the patients diagnosed as DJS before $10 \mathrm{y}$ of age have mutations involving one of the two $\mathrm{ABC}$ of the MRP2 protein whereas mutations involving domains other than $\mathrm{ABC}$ of the MRP2 protein are observed mostly in adults (see Table 2). The possible explanation is that mutations within or near the $A B C$ of the $M R P 2 / A B C C 2$ gene are related to the earlier onset of DJS. This provides a possible correlation between genotype and phenotype of DJS. Although a significant result could not be drawn from current available cases, some trends indicating the association between the type of mutation and the onset of symptomatic DJS were observed. Further investigation of more cases is needed in the future.

The reported missense mutations involving the two $\mathrm{ABC}$ in the MRP2 include G676R and R768W in the first $A B C$ and Q1382R in the second $\operatorname{ABC}(11,13,17,18)$. The functional study showed that $\mathrm{R} 768 \mathrm{~W}$ causes deficient maturation and impaired sorting of protein, Q1382R impairs the substrateinduced ATP hydrolysis, and Del R1392, M1393 leads to impaired maturation and trafficking of protein from endoplasmic reticulum (ER) to the Golgi complex $(19,20)$. The E1352Q of patient A is located between the Walker A motif and the signature $\mathrm{C}$ motif of the second $\mathrm{ABC}$ and is highly conserved in all mammalian MRP2 protein. The predicted effect of E1352Q is impairment of the function of the second $\mathrm{ABC}$.

Three nonsense mutations (R100X, R1066X, and R1310X) and one deletion mutation (Del R1392, M1393) have been described previously, leading to the failure of hepatocytes to express the MRP2 normally and were confirmed by the absence of an intact MRP2 by immunohistochemistry $(10,16)$. The 3615 del229 of patient A, 2748del136 of patient B, and Del3399-3400 of patient $\mathrm{C}$ all resulted in frame shift and the introduction of premature termination in the following exons. The predicted effects of these mutations are a truncated MRP2 protein due to disruption of the synthesis of MSD3 and a loss of the second $\mathrm{ABC}$.

Two mutations (R1150H and I1173F) involving MSD3 of the MRP2 protein, a highly conserved domain, have been described previously in DJS patients $(33,34)$. The functional assay showed that expression of MRP2 protein in the I1173F mutant was low and mislocated to the ER, whereas in the $\mathrm{R} 1150 \mathrm{H}$ mutant protein, it matured and localized properly $(15,20)$. The L441M and R393W found in patient C and D, respectively, are missense mutations within a highly conserved region in MSD2. L441M is a novel mutation whereas R393W has been lately reported (30).

In conclusion, we found four DJS patients of Chinese descent with novel mutations of the $A B C C 2$ gene. Two of them were confirmed to have neonatal onset conjugated hyperbilirubinemia, mutations involving the $\mathrm{ABC}$ and negative immunohistochemical staining for MRP2. Together with genotype-phenotype correlations in reported childhood cases of 
DJS, we suggested that disruptions of functionally important $\mathrm{ABC}$ domains in the MRP2 protein maybe related to the earlier onset of the disease. Long-term follow-up of a neonatal-onset case is mandated because DJS may have a biphasic pattern of jaundice attack, with a second attack occurring after adolescence. Careful evaluation of all cases of neonatal jaundice to rule out DJS is suggested, especially in patients with conjugated hyperbilirubinemia with mild or minimally elevated transaminase levels.

Acknowledgments. The authors thank Yu-Jung Liu, Chao-Yi Wu, and Tien-Jui Lee for technical assistance.

\section{REFERENCES}

1. Dubin IN, Johnson FB 1954 Chronic idiopathic jaundice with unidentified pigment in liver cells: new clinicopathologic entity with report of 12 cases. Medicine 33:155-197

2. Shani M, Seligsohn U, Gilon E, Sheba C, Adam A 1970 Dubin-Johnson syndrome in Israel. I. Clinical, laboratory, and genetic aspects of 101 cases. Q J Med 39:549-567

3. Kondo T, Kuchiba K, Ohtsuka Y, Yanagisawa W, Shiomura T, Taminato T 1974 Clinical and genetic studies on Dubin-Johnson syndrome in a cluster area in Japan. Jpn J Hum Genet 18:378-392

4. Kartenbeck J, Leuschner U, Mayer R, Keppler D 1996 Absence of the canalicular isoform of the MRP gene-encoded conjugate export pump from the hepatocytes in Dubin-Johnson syndrome. Hepatology 23:1061-1066

5. Keitel V, Kartenbeck J, Nies AT, Spring H, Brom M, Keppler D 2000 Impaired protein maturation of the conjugate export pump multidrug resistance protein 2 as a consequence of a deletion mutation in Dubin-Johnson syndrome. Hepatology 32:1317-1328

6. Taniguchi K, Wada M, Kohno K, Nakamura T, Kawabe T, Kawakami M, Kagotani K, Okumura K, Akiyama S, Kuwano M 1996 A human canalicular multispecific organic anion transporter (cMOAT) gene is overexpressed in cisplatin-resistant human cancer cell lines with decreased drug accumulation. Cancer Res 56:41244129

7. Deeley RG, Cole SP 1997 Function, evolution, and structure of multidrug resistance protein (MRP). Semin Cancer Biol 8:193-204

8. Tate G, Li M, Suzuki T, Mitsuya T 2002 A new mutation of the ATP-binding cassette, sub-family $\mathrm{C}$, member 2 (ABCC2) gene in a Japanese patient with Dubin-Johnson syndrome. Genes Genet Syst 77:117-121

9. van Kuijck MA, Kool M, Merkx GF, Geurts van Kessel A, Bindels RJ, Deen PM, van Os, CH 1997 Assignment of the canalicular multispecific organic anion transporter gene (CMOAT) to human chromosome 10q24 and mouse chromosome 19D2 by fluorescent in situ hybridization. Cytogenet Cell Genet 77:285-287

10. Paulusma CC, Kool M, Bosma PJ, Scheffer GL, ter Borg, F, Scheper RJ, Tytgat GN, Borst P, Baas F, Oude Elferink, RP 1997 A mutation in the human canalicular multispecific organic anion transporter gene causes the Dubin-Johnson syndrome. Hepatology 25:1539-1542

11. Wada M, Toh S, Taniguchi K, Nakamura T, Uchiumi T, Kohno K, Yoshida I, Kimura A, Sakisaka S, Adachi Y, Kuwano M 1998 Mutations in the canalicular multispecific organic anion transporter (cMOAT) gene, a novel ABC transporter, in patients with hyperbilirubinemia II/Dubin-Johnson syndrome. Hum Mol Genet 7:203-207

12. Kajihara S, Hisatomi A, Mizuta T, Hara T, Ozaki I, Wada I, Yamamoto K 1998 A splice mutation in the human canalicular multispecific organic anion transporter gene causes Dubin-Johnson syndrome. Biochem Biophys Res Commun 253:454-457

13. Toh S, Wada M, Uchiumi T, Inokuchi A, Makino Y, Horie Y, Adachi Y, Sakisaka S, Kuwano M 1999 Genomic structure of the canalicular multispecific organic anion-transporter gene (MRP2/cMOAT) and mutations in the ATP-binding-cassette region in Dubin-Johnson syndrome. Am J Hum Genet 64:739-746
14. Tsujii H, Konig J, Rost D, Stockel B, Leuschner U, Keppler D 1999 Exon-intron organization of the human multidrug-resistance protein 2 (MRP2) gene mutated in Dubin-Johnson syndrome. Gastroenterology 117:653-660

15. Mor-Cohen R, Zivelin A, Rosenberg N, Shani M, Muallem S, Seligsohn U 2001 Identification and functional analysis of two novel mutations in the multidrug resistance protein 2 gene in Israeli patients with Dubin-Johnson syndrome. J Biol Chem 276:36923-36930

16. Shoda J, Suzuki H, Suzuki H, Sugiyama Y, Hirouchi M, Utsunomiya H, Oda K, Kawamoto T, Matsuzaki Y, Tanaka N 2003 Novel mutations identified in the human multidrug resistance-associated protein 2 (MRP2/ABCC2) gene in a Japanese patient with Dubin-Johnson syndrome. Hepatol Res 27:323-326

17. Wakusawa S, Machida I, Suzuki S, Hayashi H, Yano M, Yoshioka K 2003 Identification of a novel $2026 \mathrm{G} \rightarrow \mathrm{C}$ mutation of the MRP2 gene in a Japanese patient with Dubin-Johnson syndrome. J Hum Genet 48:425-429

18. Materna V, Lage H 2003 Homozygous mutation Arg768Trp in the ABC-transporter encoding gene MRP2/cMOAT/ABCC2 causes Dubin-Johnson syndrome in a Caucasian patient. J Hum Genet 48:484-486

19. Hashimoto K, Uchiumi T, Konno T, Ebihara T, Nakamura T, Wada M, Sakisaka S, Maniwa F, Amachi T, Ueda K, Kuwano M 2002 Trafficking and functional defects by mutations of the ATP-binding domains in MRP2 in patients with Dubin-Johnson syndrome. Hepatology 36:1236-1245

20. Keitel V, Nies AT, Brom M, Hummel-Eisenbeiss J, Spring H, Keppler D 2003 A common Dubin-Johnson syndrome mutation impairs protein maturation and transport activity of MRP2 (ABCC2). Am J Physiol Gastrointest Liver Physiol 284:G165-G174

21. Kondo T, Yagi R, Kuchiba K 1975 Letter: Dubin-Johnson syndrome in a neonate. N Engl J Med 292:1028-1029

22. Lo NS, Chan CW, Hutchison JH 1979 Dubin-Johnson syndrome with some unusual features in a Chinese family. Arch Dis Child 54:529-533

23. Shieh CC, Chang MH, Chen CL 1990 Dubin-Johnson syndrome presenting with neonatal cholestasis. Arch Dis Child 65:898-899

24. Kimura A, Ushijima K, Kage M, Mahara R, Tohma M, Inokuchi T, Shibao K, Tanaka N, Fujisawa T, Ono E 1991 Neonatal Dubin-Johnson syndrome with severe cholestasis: effective phenobarbital therapy. Acta Paediatr Scand 80:381-385

25. Tsai WH, Teng RJ, Chu JS, Chang MH, Ho MM 1994 Neonatal Dubin-Johnson syndrome. J Pediatr Gastroenterol Nutr 18:253-254

26. Nakata F, Oyanagi K, Fujiwara M, Sogawa H, Minami R, Horino K, Nakao T, Kondo T 1979 Dubin-Johnson syndrome in a neonate Eur J Pediatr 132:299-301

27. Haimi-Cohen Y, Merlob P, Marcus-Eidlits T, Amir J 1998 Dubin-Johnson syndrome as a cause of neonatal jaundice: the importance of coproporphyrins investigation. Clin Pediatr 37:511-513

28. Regev RH, Stolar O, Raz A, Dolfin T 2002 Treatment of severe cholestasis in neonatal Dubin-Johnson syndrome with ursodeoxycholic acid. J Perinat Med 30:185-187

29. Chen HL, Chen HL, Liu YJ, Feng CH, Wu CY, Shyu MK, Yuan RH, Chang MH 2005 Developmental expression of canalicular transporter genes in human liver. J Hepatol 43:472-477

30. Machida I, Wakusawa S, Sanae F, Hayashi H, Kusakabe A, Ninomiya H, Yano M, Yoshioka K 2005 Mutational analysis of the MRP2 gene and long-term follow-up of Dubin-Johnson syndrome in Japan. J Gastroenterol 40:366-370

31. Ito S, Ieiri I, Tanabe M, Suzuki A, Higuchi S, Otsubo K 2001 Polymorphism of the $\mathrm{ABC}$ transporter genes, MDR1, MRP1 and MRP2/cMOAT, in healthy Japanese subjects. Pharmacogenetics 11:175-184

32. Kikuchi S, Hata M, Fukumoto K, Yamane Y, Matsui T, Tamura A, Yonemura S, Yamagishi H, Keppler D, Tsukita S, Tsukita S 2002 Radixin deficiency causes conjugated hyperbilirubinemia with loss of Mrp2 from bile canalicular membranes. Nat Genet 31:320-325

33. Tomer G, Ananthanarayanan M, Weymann A, Balasubramanian N, Suchy FJ 2003 Differential development regulation of rat liver canalicular membrane transporters Bsep and Mrp2. Pediatr Res 53:288-294

34. Belinsky MG, Bain LJ, Balsara BB, Testa JR, Kruh GD 1998 Characterization of MOAT-C and MOAT-D, new members of the MRP/cMOAT subfamily of transporter proteins. J Natl Cancer Inst 90:1735-1741

35. Kool M, de Haas, M, Scheffer GL, Scheper RJ, van Eijk, MJ, Juijn JA, Baas F, Borst P 1997 Analysis of expression of cMOAT (MRP2), MRP3, MRP4, and MRP5, homologues of the multidrug resistance-associated protein gene (MRP1), in human cancer cell line. Cancer Res 57:3537-3547 